\title{
Argument Has No Function
}

\section{JeAn GoOdwIN Iowa State University}

\begin{abstract}
Douglas Walton has been right in calling us to attend to the pragmatics of argument. He has, however, also insisted that arguments should be understood and assessed by considering the functions they perform; and from this, I dissent. Argument has no determinable function in the sense Walton needs, and even if it did, that function would not ground norms for argumentative practice. As an alternative to a functional theory of argumentative pragmatics, I propose a design view, which draws attention to the way participants strategically undertake and impose norms on themselves in order for their arguments to have force.
\end{abstract}

Résumé: Douglas Walton a eu raison d'attirer notre attention sur les aspects pragmatiques des arguments. Toutefois, il a insisté qu'on devrait interpréter et évaluer des arguments en prenant compte de leurs fonctions. Je suis en désaccord avec ceci: on ne peut pas déterminer les fonctions des arguments dans le sens dont Walton a besoin, et même si on le pouvait, on ne pourrait pas fonder les normes de l'argumentation sur ces fonctions. Je propose comme alternative à la théorie fonctionnelle de la pragmatique argumentative une théorie qui concentre sur la façon que des participants planifient stratégiquement et imposent des normes sur eux-mêmes afin de renforcer leurs arguments.

Keywords: argument; argumentation; argument-evaluation; informal-logic; Walton, Douglas; functionalism; dialogue; dialectics; pragmatics.Argument has no function

\section{Introduction}

Over the last twenty years, Douglas Walton has been leading the way to the pragmatic study of argument. Throughout his extensive body of work he has urged us to look at actual arguments, insisting that the goodness of an argument can only be assessed in its real-world context. He has called on us to recognize: that an arguer makes an argument for a purpose-not uncommonly, because she is obliged to address an issue between herself and others; that her obligations at any moment depend in key ways on what she and others have said before; that as argumentative talk proceeds, her argument often ramifies beyond a simple premise/conclusion pairing into more complex patterns; that the situatedness and complexity of argument legitimately leaves room for the arguer to make strategic choices in the design of what she does. Walton has also reminded us that our job as theorists is to use care in sorting out and systematizing the patterns in argumentative talk (strategies, schemes, speech acts etc.), and good judgment in assessing its quality. 
This pragmatic approach has opened new questions for theory. What kind of story should we tell about the relationship of an argument to its context? How should we conceptualize or model "context"? - what are its most relevant features? What are the norms by which arguments-in-context should be evaluated?

Consider this as an example-one I'll be using as a test case occasionally in this paper. It is widely recognized by both theorists and practitioners of argument that in some contexts, some arguers have a burden of proof: an obligation to produce arguments of a certain quality. For instance, at times an arguer is obliged to reply to objections of some sort. In such a case, to be good, an argument must (among other things) meet the contextually-given obligations. So we need to ask: Where do probative obligations come from? What features of the context give rise to them? It seems obvious that prior talk is often relevant to establishing burdens of proof, while the phase of the moon is not. But why? And what aspects of the prior talk? Context is important. But a pragmatic theory of argument must go on to give an account of how, in at least some specific contexts, the burden of proof is in fact assigned.

Walton has led the way in this, as well. He has made what I am going to call a function claim, proposing that the most important feature of the context of an argument is the social function that the surrounding talk is performing. In this paper, I contend that function claims lead us astray. Argument is indeed useful. But argument has not been shown to have any function, in the specific sense I am using it here; and even if it does have a function, we cannot derive norms from that fact. We need to stop making function claims, and take up other ways of conceptualizing context. I close by proposing one such alternative.

\section{Function claims: what, who, why}

All would probably agree that argument is functional, in a broad sense. People aren't insane when they make arguments. In general, they are trying to get something done, and they expect their arguments make a difference. All discourse is functional in this sense (e.g., Sanders, 2005), and argumentative discourse is no exception. Many of us, furthermore, think good argument is necessary for the human species to flourish, or even survive. And so we might say that argument performs a vital function.

I strongly endorse the functionality (purposiveness, usefulness, value, effectiveness, dignity) of argument in this broad sense. The functionalism that I am objecting to, by contrast, is a specific mode of theory construction-a specific way of modeling the general functionality of argument. For the purposes of this paper, an explicit function claim consists of the following complex of assertions:

(a) The context of an argument should be conceived as a joint activity. ${ }^{1}$

(b) That joint activity has the function of achieving a social good.

(c) The norms of argument include those rules (principles, values, 
standards, etc.) an argument must follow (live up to, instantiate, meet, etc.), in order for the joint activity in which it is embedded to achieve its function.

Douglas Walton has been one of the most prominent theorists making a function claim, as the following brief review of his theory reminds us.

(a) Arguments, for Walton, occur in the "standard contexts" $(1995,98)$ provided by "joint activities" $(1998,29)$ called dialogues. As he defines it,

a dialogue is a conventionalized framework of goal-directed activity in which two participants interact by taking turns to perform speech acts. . . The various speech acts are linked together in a sequence that has a purpose and direction as the dialogue proceeds. The purpose is determined by the goal of the dialogue as a recognized type of social activity (1995, 98; see also, e.g., 2006, 2; 1998, 29).

A dialogue thus provides a mutually recognized, shared framework or structure within which the individual activities of the arguers take place. As is well known, Walton envisions multiple types of dialogue; a standard list includes persuasion dialogues, negotiations, deliberations, inquiries, information-seeking dialogues and quarrels (e.g., 1998), but in other places he mentions up to eleven types (1992, 95), with further divisions into subtypes possible.

(b) Participants in a dialogue have their own individual aims, but these, Walton insists, must be distinguished from the collective goal that defines the dialogue itself (Walton \& Krabbe, 1995, 67; Walton, 1995, 101). "What is important" for argumentation theory, he says, "is not the particular arguer's purpose but the purpose of the dialogue as a whole" $(1995,271)$. The collective purpose. goal or aim of a given type of dialogue is to realize a recognizably valuable state of affairs shared by the participants - that is, a social good. A persuasion dialogue aims at resolving or clarifying issues; an inquiry aims to prove or disprove a hypothesis; a negotiation aims at a reasonable settlement that both parties can live with; deliberation aims to decide the best available course of action to be taken $(2006,183)$. Even a quarrel achieves a social good. Individual participants may want to hurt each other, but the dialogue can "reveal [the] deeper basis of conflict" (2006, 183), in the hope that once "hidden grievances" are "exposed explicitly, acknowledged and dealt with," the "continuance of a personal relationship" will prove possible. "During a good quarrel, the participants 'make up,' . . . vowing to be more thoughtful or sensitive about this particular issue in future conduct $(1995,109)$. The quarrel, in Walton's view, thus performs a "cathartic function" $(2006,190)$.

(c) A dialogue provides a normative framework for arguments, and Walton derives the norms from the collective goal of the dialogue. Indeed, Walton argues that it the normative force provided by a dialogue's goal-directedness that differentiates his approach from the formal dialectics of Hamblin and others. Such dialogue games, although interesting, fail to model well real-world argumentative discourse because they are not "motivated" by the purposes actual dialogues are 
aimed to achieve. It is the collective goal of the exchange, Walton explains, that allows us to pin down the exact dialectical norms that bear within it, among all the possibilities formal systems offer $(1995,8)$.

How does a dialogue's collective goal determine the norms that bear within it? Most generally, norms for argumentative talk arise because participants in a dialogue ought to cooperate to achieve the collective goal. In various works, Walton applies this general principle to a variety of specific questions within argumentation theory. For example, the dialectical rules of procedure are just those that "guarantee or at least facilitate the reaching of [a given dialogue's] goal" (Walton \& Krabbe, 1995, 66). Argument assessment depends on the collective goal: to say that an argument is good "in the functional or pragmatic sense ... means that the argument is good or useful in contributing to the goal of the dialogue" $(1998,43)$. Fallacies are given a "functional" account; a fallacy is committed when an argument scheme is used "in a manner that fouls up" a dialogue, "block[ing] or subvert[ing]" its goal (1995, 22-23). An argument has a linked as opposed to convergent structure if all its premises must "function together" in order to achieve the argument's purpose in the context of dialogue (1996a, 176-77). Relevance is established when an argument is locally or globally appropriate to achieving a dialogue's goal; irrelevance, when an argument is "unproductive" for it $(2006,272)$. Or consider finally Walton's derivation of the burden of proof. He comments:

The concept of an obligation applies to all types of dialogue. The obligation is the function the participant has to perform, according to the rules of the dialogue, in order to fulfill his goal in the dialogue. Burden of proof is a subcategory of obligation. . . . Burden of proof is an important and useful idea where conclusive resolution of a disputed issue by appeal to decisive evidence (knowledge) is not practical or possible. The problem, in such a case, is that argumentation could go on and on and never reach a resolution. Burden of proof is a practical solution to this problem which works by setting a required weight of strength of argumentation as sufficient to prove (disprove) the contention, and thereby close the dialogue off from further argumentation (1996b, 24).

In sum, Walton puts forward what he himself calls a "functional view of argument" (1992, xii), (a) locating arguments within the contexts of dialogues of specific types, (b) dialogues which are aimed to achieve specified social goods, (c) a social goods which ground context-dependent norms for arguments.

Walton is not alone in making a function claim. He is joined most notably by the pragma-dialecticians. As is well known, they propose (a) that an argument is to be "view[ed] . . . as part of a critical discussion." A critical discussion (b) is a speech activity "aimed at resolving a difference of opinion." It is regulated (c) by a "valid dialectical procedure," where validity

depend[s] on how efficient and efficacious it is in furthering the resolution of disagreement. . . . A valid dialectical procedure makes it possible to determine whether the argumentative discourse as it is conducted can be instrumental in resolving a difference of opinion. 
So as a sort of shorthand they say: "argumentation has the general function of managing the resolution of disagreement" (van Eemeren et al., 1996, pp. 278, 280, $278,277) .^{2}$

And Ralph Johnson is another. "To understand the product that we call an argument," he says, (a) "it is necessary to situate it within its proper context: the practice of argumentation." Unlike a dialogue or critical discussion, the practice of argumentation is not a specific event (or process) of argument exchange; instead, in the terms I am using here, the practice of argumentation is a joint activity at the most general level. It is, in Johnson's words, the widely recognized, socially instituted "sociocultural activity" of exchanging arguments, the "shared understanding" of which makes specific events intelligible. The practice of argumentation, furthermore, (b) achieves certain goals "internal" to it, including: "an increase in rationality and specifically a deeper understanding, and-or being rationally persuaded, and-or coming closer to an acceptable position." Finally, (c) "a good argument is one that fulfills its purpose" by meeting the requirements Johnson establishes as necessary to achieve these internal goods $(2000,154,155$, 181).

Other theorists, while not articulating full function claims, do use language that echoes one or more of assertions (a), (b) and (c). This suggests that they may be committed to functionalism, or at least are tending in that direction. Signs that may indicate an implicit function claim include:

(a)-like talk: Naming the joint activity in which arguments are said to occur. Many theorists start theorizing the context of argument by conceiving the context "whole," taking a top-down approach in line with (a). For these theorists, the most interesting thing about argument is that it occurs within the context of a (insert noun here). For example, Freeman contends that the "basic dialectical situation can serve as a model of argument" (1991, 20). Such a baptizing of a context suggests that a theorist may be leaning towards a function claim.

(b)-like talk: Using purpose-language without a purpose-er. Some theorists ascribe aims, goals, ends, purposes (etc.) not to the people using arguments, but to the joint activity or argument itself. For example, Michael Gilbert, who is generally quite precise in referring to arguers' goals, occasionally lapses into such language, asserting that "the aim of coalescent argumentation is to bring about an agreement between two arguers based on the conjoining of their positions in as many ways as possible" (1997, 70). Similarly, Trudy Govier remarks that "the purpose of an argumentative exchange is to communicate information, beliefs, and opinions [etc.]" (1987, 149). As Jon Elster (1982) has remarked, "functionalist thinkers characteristically use the passive voice;" when an argumentative activity is said to aim at something, a function claim may be lurking.

(c)-like talk: Invoking an obligation to cooperate. An asserted function of argument can be taken to regulate the behavior of individual arguers by way of their alleged obligation to cooperate in a joint activity to achieve it; cooperation is 
the glue binding an empirical function to a norm of argumentation. Walton frequently invokes the name of Grice in this regard, quoting "Cooperative Principle" (e.g., $1998,5 ; 1996 a, 23 ; 1995,255 ; 1992,84)$, and other theorists have done the same (e.g., Govier, 1987, 156). ${ }^{3}$ Invocations of an obligation to cooperation should count as signs of a possible function claim .

Given their apparent popularity, we have to grant that function claims have their attractions. First, a functional approach solves many problems in theory, quickly. Instead of building a theory of context bit by bit, figuring out which aspects of context are important for which aspects of argument and why, a function claim conceives of the context of an argument entire, as a gestalt or organism; only later need it work from top down to deal with the messy details. Second, function claims resonate well with the apologetics we use to defend the legitimacy of our enterprise. In order to persuade (say) students and administrators of the importance of the argumentation course, we like to proclaim how useful-indeed vital -it is for achieving all sorts of important objectives. (And, as I said above, we're right.) Finally, it's just easy to talk function talk. It is a vocabulary that seems ready to hand when we want to discuss social life.

In fact, the vocabulary is ready to hand; we are far from the first to adopt it. The earliest attempts to explain social activity in terms that would meet the standards of modern scholarship adopted a functionalist perspective. By the 1950s and 1960s, however, early functionalism in sociology and anthropology had come under intense critique, and by the late 1960 s was at least temporarily defunct. ${ }^{4}$ In the following, I draw from many of the issues that were raised in this debate to argue that we too should abandon naïve function claims.

There are problems with each of the three component assertions of a function claim. Start with (a). Personally, I have what might be called ontological doubts about the alleged joint activities within which arguments are said to be used. Arguments are everyday things; we're intimate with them. So it seems odd to me to explain them by reference to abstract social institutions, some of which do not even have names in ordinary language (see also Dore's (1967) critique of the tendency to treat "institutions . . . as ultimate units"). Further, the move in (a) seems suspiciously like assuming the conclusion: instead of working his way to more and more sophisticated theories of context, the theorist finds that everything he needs to know about the context of argument is already implicit in the conception of the joint activity. This is theory without tears.

It is beyond the reach of this paper, however, to question the conditions for saying that an institution - what Durkheim called a "social fact"-really exists. Therefore I am going to focus my objections here on moves (b) and (c) of the function claim. In the following, I argue that there has been no showing that the (assumed) joint activities within which arguments occur have the asserted functions (anti-(b)). And even if there are such functions, they are not sufficient to justify specific norms of argument (anti-(c)). But that's not a problem, I will conclude, 
since there is at hand another way of conceptualizing context—one which does not make a function claim.

\section{Argument has yet to be shown to have a function}

\subsection{Where is the evidence?}

In move (b), theorists like Walton making function claims assert that the joint activities within which arguments are embedded perform specified functions. To say that something performs a function is to say it normally or reliably does something, that it has consequences, in particular, socially useful consequences. To borrow a more precise definition from Robert Merton, one of the most sophisticated of the functional sociologists: "Functions are those observed consequences [of a social institution] which make for the adaptation or adjustment of a given [social] system" $(1957,51)$. Thus for Walton, argumentative dialogues "adjust" our social system by promoting rational consensus, mutual understanding, sound decisions and solid relationships. Other theorists noted above postulate something like "rational dispute resolution" to be the (or a) function of argument; so they appear to think that a reason-based consensus is a regular consequence of some argumentative activities.

So my question is: How do these theorists know that the joint activity in fact produces socially useful consequences like this? Where's their evidence? Shouldn't it be easy, or at least possible, to show a significant case in which an argumentative joint activity has promoted mutual understanding, rational consensus and so on? Or alternatively, some statistics suggesting a correlation between an increase in argumentative talk in some society, and an increase in mutual understanding (etc.) there?

Unfortunately, no such evidence is being produced. Quite the contrary: move (b) typically occurs at the very beginning of theorizing; theorists appear to treat it as so obvious as to need no defense (either that, or it is a matter of stipulation-a possibility I will return to in 2.4 .3 below).

Early functional analysis in sociology sank in part because of just such complaints. Even Merton himself decried the fact that sociological functionalists "do not typically carry through operationally intelligible procedures, [and] do not systematically assembled needed types of data" $(1957,49)$. Others complained that functions were established "intuitively by the structure of the observer's language, or are assumed to be in nature"" (Davis, 1967, 387, quoting Buckley, "Structural-Functional Analysis in Modern Sociology").

The lack of evidence might be forgiven. At least some of the claimed functions of argument are plausible, and if we had no reason to believe that they were wrong, we might continue to accept them as the best currently available accounts of what argumentative joint activities do. But we do have evidence of other possibilities, or at least can imagine some. Consider three sources of evidence: sociological studies, ordinary experience, and speculation. 


\subsection{Some other consequences of argument}

(1) Argument is functional, but in odd ways. There are a handful of empirical studies examining the function of argumentative activities, suggesting several possibilities. Deborah Schiffrin's early "Jewish Argument as Sociability" (1984), for example, gave evidence that argument can be an activity participants engage in for its own sake and to maintain their relationships, not to resolve substantive issues. Gary Fine's (2001) study of high school debaters supported the idea that their argumentative activity allows bright adolescents to experiment with the line between acceptable and unacceptable behavior, for example by trying out arguments which are outrageous but (within the local rules) valid.

Unfortunately, neither of these documented functions are among those thus far proposed by argumentation theorists, nor do they seem useful for producing the kinds of norms theorists want to produce in move (c) of the function claim.

(2) Argument is dysfunctional. So turn to ordinary experience. The most salient consequence of the joint activities involving arguments is to make the participants mad: this is at least a widely held ordinary view of the function of argument. It is easy to elicit this view from students (Goodwin, 2005b) — as I am sure most of my readers would agree. Indeed, a connection between "argument" and "war" may be built into our very language, with its conventionalized metaphors like "attacking" and "defending" positions (thus Lakoff \& Johnson,1980; see also the covers of several well-known argument texts). And even a linguist like Deborah Tannen proceeds as if the "argument" aspects of the "argument culture" lead inevitably to confrontations and fighting (1998).

But if increased hostility is the most salient outcome of the joint activities in which arguments arise, then these activities are not so much functional as dysfunctional, decreasing the "adaptation or adjustment" of the social system. Hostility is not a social good but a social ill; we do not want to promote hostility by establishing norms.

(3) Argument is consequential, but not functional. One of the leading alternatives to functionalist sociology in the 1960s was a Marxism-inspired "conflict theory." In this view, social institutions are not in place because they are functional; they are there (to speak very generally) because those with power have put them there, to help maintain their power.

So consider this speculation-a story about argumentative activities that runs along the parallel lines. In our society, the resources for making arguments are not equally distributed. The rich and powerful have more access to the education, information and self-confidence necessary to argue well. So, we can imagine, they institute the exchange of arguments as a means of resolving disputes, since these exchanges are games they are likely to win.

The powerful also have an interest in maintaining an ideology or false consciousness that "dialogues reach rational resolution" and that "argumentative activities benefit all." That way, when the powerless lose the argument—as, being 
handicapped, they often will-they will blame themselves, not the social injustices, for their defeat.

We can even project how argumentative "norms" could arise on this view. Return for example the burden of proof as articulated within forensic debates in U.S. colleges: anyone who proposes a change in the status quo is obliged to make a prima facie case for that change. As Tom Goodnight pointed out at the inaugural Alta conference, this burden of proof assignment instantiates a specifically conservative political philosophy (1980). One could hypothesize that it is imposed by those currently victorious in the social struggle as a repressive measure against those who are currently losing in it. After all, the weight of the obligation explicitly rests on those who would change things.

Lest this account seem too far-fetched, let me point out that similar objections have been put forward, especially by feminist scholars, in opposition to current political theories that stress deliberation (e.g., Sanders, 1997; Young, 1996). In an unjust society, what purports to be a cooperative exchange of reasons really perpetuates patterns of oppression.

Like the functional account, this hypothetical "conflict theory" conception of joint argumentative activity stresses its social consequences: here, the consequence of maintaining the powerful in power. This consequence is neither functional nor dysfunctional, however; it does not either work to the benefit or detriment of society as a whole. That is because a "conflict theory" does not conceive of society as being a whole, as naïve functionalism does. Instead, argumentative activities are seen as benefiting some groups, hurting others. From this point of view, function claims are not just false, they are ideologically driven, inherently conservative attempts to mask injustice — a common complaint against functionalist theories (see Demerath \& Peterson, 1967 and Abrahamson, 1978).

And so again, we have a plausible (if speculative) account of what joint activities involving argument can do, but one that doesn't assert that they achieve a social good. Given the existence of these three alternatives-the odd functions, dysfunctions and non-functions of argumentative activities-it seems reasonable to ask those making function claims to produce some evidence in support of their alleged function(s).

\subsection{The special problems of multiple joint activities}

Before turning to answer some objections, let me insert an aside about Walton's pluralistic version of the function claim.

To some extent, this approach seems to avoid my complaints about lack of evidence, since whatever function I can document, experience or imagine, a multifunctionalist can probably absorb. Yes, Walton may say, arguments can contribute to joint activities which resolve disputes; but they can also contribute to emotional release_-and, as far as we know, to sociability and class warfare as well. 
My question to multi-functionalists like Walton is instead: given this wide range of possible joint activities or "dialogue types," how do you know which one is being actualized in any specific argumentative transaction? For unless the collective goal of a joint activity can be securely identified, the norms governing it cannot be derived and applied.

Walton is in fact quite candid about this problem. The dialogue type in play at a given moment "may not be clearly specified or apparent" $(1992,43)$. Further, a dialogue may be of one type, but have a "flavor or overtone" of another (Walton \& Krabbe, 1995, 70); it may even be a mixture of several types (e.g., 1998, c. 9). Indeed, some of our most prominent actual argumentative joint activitiesinstitutions which are named in ordinary language, possess explicit rules, and sustain rich normative practices-institutions which even an institution-agnostic like myself finds hard to doubt - these very institutions Walton finds to be the most mixed, according to his typology. "Political debate" (that is, formal debate in a legislature) "is typically a complex mixture of all six types of dialogue," Walton says (1995, 128). Similarly, the closing arguments of trials in the common law system, while being mostly persuasion dialogues, also have elements of expert consultation dialogue, negotiation, and probably eristic as well. But if norms are to be derived from the collective goal of a dialogue, how are we to determine what they are when so many goals are in play? Although of course "special sensitivity and qualifications" will always be required to discern and apply norms of argument to complex, real-world situations $(1998,218)$, as functionalism becomes too multi-, it loses its explanatory power. ${ }^{5}$

It's worth noting that this is not just a problem for argumentative theorists. Arguers in practice also need to figure out what norms they should be following. As Walton confesses, given the multiple possible goals of argumentative joint activities, "participants in argumentation are often unclear as to what type of dialogue they are supposed to be engaged in" $(1995,129)$, or if clear, they may disagree $(1995,123)$. So how do participants come to a mutual understanding about which dialogue type they are pursuing? (As in the Monty Python sketch, what if one person wants an argument, but the other thinks he needs abuse?) Walton occasionally speaks as if participants in an argumentative joint activity start by reaching an agreement about what kind of dialogue they will have (e.g., 1998, 205). Since argumentative talk often begins because people disagree, it seems unrealistic to assume that they will reach such procedural agreements easily. For example, in many contemporary controversies each side claims that the other has the burden of proof (Gaskins, 1992). Who is right? Presumably, participants in an argumentative dialogue will need to have a meta-dialogue to establish the goal and thus the norms of their joint activity. But what type of dialogue will that be? An infinite regress seems to threaten.

In fact, we solve this sort of problem in practice all the time. I call a student into my office, or I get called in by my dean. What kind of conversation are we 
two going to have? In general, in our society the higher status person can try to set the tone-"waiving" formality, for example, or starting angrily. The other may go along — or may not; one can refuse to sit when invited, for example. The norms and other expectations governing a particular interaction arise out of the strategic actions of the participants themselves.

Examples like these suggest the following thought. Even if we assume that arguers have a set of joint activities and associated norms "at hand," each will still need strategies for bringing his desired activity-cum-norms to bear on the immediate situation. These strategies are not part of the joint activity; they need to be theorized on their own (for some indications of how to do this, see Section 4 below). So a functionalist theory, even in its multi-functionalist variation, remains at a minimum radically incomplete.

\subsection{Some objections answered}

(1) It could be said that functions like "sociability" and "enabling experimentation" are merely parasitic on the "real," "central," or "paradigmatic" function of argumentative talk, that is, rational resolution of disputes (or whatever). So the existence of these odd functions does not undermine move (b) of the function claim.

Fine! But note, that should make it even easier to find some evidence that rational resolution (or whatever) is the, or even a, regular consequence of argumentative talk, given that it is so central and paradigmatic.

(2) It could be said that the ordinary views and my "conflict" hypothesis do not undermine the existence of a function for argumentative talk. For following functionalist theorizing in sociology (e.g., Merton 1957), the "manifest" and "latent" functions of the joint activity could be distinguished. The "manifest" functions are those apparent to participants, as for example the function of making people mad; hidden from them, although visible to the skilled investigator, are the real, "latent" functions the activity achieves. It could even be that the hidden, latent functions of an activity are achieved precisely because of its manifest dysfunctionality, by a sort of "invisible hand" (more on this below). Indeed, I've heard the pragmadialecticians say just this: the more hostile arguers are-the more they want to defeat each other - the more they are motivated to produce high quality arguments, and thus the more functional their joint activity becomes. So the existence of dysfunctions or conflicts does not undermine move (b) of the function claim.

Again, fine! But to assert that something is the latent function of an activity suggests that it is even more important for the skilled investigator to produce some evidence for its existence, given that the function is by definition not apparent to most of us.

(3) Finally, it could be said that argumentation theory is not a branch of sociology; in making function claims, we are not trying to describe or explain a social activity, 
we are trying to develop norms for it. Whatever the observed consequences of the joint activities within which arguments are embedded-whether there are any observed consequences at all—still, arguers ought to pursue the activities in order to achieve the social goods the theorist posits. As Walton puts it, "the structures of dialogue" he proposes

are normative models that represent ideals of how one ought to participate in a certain type of conversation if one is being reasonable and cooperative. It is important not to confuse this with an account of how participants in argumentation really behave in instances of real dialogue that take place (Walton \& Krabbe, 1995, 67).

Similarly, the pragma-dialecticians recognize that the function of argument is an idealization: a tool for critiquing argument activities, weeding out the dysfunctional and nonfunctional growths, and fostering whatever among the actual activities is worth salvaging. And Govier likewise has warned us that to say "that the practise or social institution of argument has [rational persuasion] as its typical function or purpose" is not to make a "straightforwardly empirical" point, but a "conceptual and normative one" (1987, 150).

But an idealization or a conceptual point about actual argumentative discourse still needs defending. For example, if rational resolution is indeed the end of some joint activity involving argument exchange, shouldn't it be paradoxical in the course of such an activity to say something like "I am making an argument (that p), but I am not trying rationally to resolve the dispute with you (that $\mathrm{p}$ )"? To me, however, that assertion does not sound strange. Indeed, although I am here making arguments that argument has no function, I am not trying to resolve the dispute about argument's function. That would be a hard ambition, since I do not expect to change the mind of anyone who has committed himself to a function claim. (I do, however, expect to force theorists to take responsibility for what they say, and thus to give them strong encouragement to think. And, being an optimist, I hope that thinking will lead them to the correct answer.)

Or if not by such a demonstration of pragmatic incompatibility, a theorist might defend an idealization by displaying its power in understanding and assessing argumentative talk. Along these lines, he might demonstrate how useful it is to treat some actual argumentative activity as if it were a "persuasion dialogue" or "critical discussion"- - how adopting the model enables him to make a more sophisticated critique of the activity than a reasonably skilled, but theoretically naïve, practitioner could. Or again, a theorist might defend an idealization by pointing to evidence that arguers in practice are orienting themselves towards the asserted norms, accumulating empirical evidence that would suggest their force.

Thus far, however, theorists making function claims have yet to muster such defenses of their idealizations. Of course, an idealization could still be interesting; it could allow theorists to explore systematically and precisely the consequences of making certain simplifying assumptions. It is possible to proceed to construct 
theory by stipulation, saying: "Let us call units of discourse which contribute in such $\&$ such a way to achieving such $\&$ such a collective goal, 'arguments." But if that's what they are trying to do, theorists making function claims run the risk of misleading their readers into thinking that they are discussing, well, argumentsthe familiar, everyday kind (see Godden, 2005 for a similar point).

But Walton in particular doesn't want the joint activities he posits to be just idealizations, like formal dialogue games. Walton finds it attractive to model argumentative activities as dialogues specifically because it seems to allow descriptive/empirical and normative/conceptual approaches to be linked (e.g., Walton, 1998, 29; Walton \& Krabbe, 1995, 175). And I believe that other theorists making function claims follow him in this. If so, it seems incumbent on them to show that the goal-directed joint activities they posit indeed articulate well the ideals implicit in actual argumentative talk.

Finally, let us assume that this task can be accomplished: that the idealizations can receive a partial defense. Still, I will argue, even as an idealization a collective goal won't do the job function theorists expect of it: it won't ground norms governing argumentative activity. To fill out that idea, I move from function claim (b) to claim (c), and open a new section.

\section{Even if argument has a function, we cannot derive norms from that fact}

\section{1 "Ought" from "is"?}

In move (c), theorists making function claims derive specific norms, binding on arguers, which purport to be necessary for the joint activity constituting the context of arguments to achieve its assigned collective goal. In principle, however, there are problems with making this move.

If the joint activity which provides the context for argument achieves, really or ideally, a social good, then certainly if we happen to be designers of social institutions we will (other things being equal) want to create conditions within which that activity will flourish. That is straightforwardly a matter of prudence.

What is not straightforward is how this prudential concern in the design of institutions translates into norms binding on individual participants in those institutions. ${ }^{6}$ This seems especially true if the alleged function of the argument activity is latent, that is, unrecognized by the participants. Every arguer undoubtedly has his own purposes. But why should he be obligated to so act as to achieve the purpose of the dialogue, especially if he is not even aware of that purpose? As an analogy: According to the "invisible hand" theory of economic activity, individual greedy behavior performs the important social function of creating wealth. If so, those setting economic policy are wise to take this fact into account, harnessing greed for the common good. Nevertheless, individual economic actors are not obliged to be greedy. Part of the excitement of this mode of theorizing is the way 
that it transforms individual vice into collective good. But vice remains vice; a functional account of an activity does not seem to impose norms on individual actors. You cannot have at once a functional theory, especially one that relies on the "invisible hand," and one that derives norms.

\subsection{The possibility of functional alternatives means that functions do not determine norms}

Let us assume, however, that those making function claims can overcome this difficulty. After all, it does seem plausible that individuals are in some fashion obliged to promote the common good, which suggests that at least manifest functions have some normative punch. But there is still a second difficulty facing move (c): showing that this specific set of norms is necessary to achieve the function.

Early functionalism in sociology and anthropology attempted to insist on the functional indispensability of certain social arrangements - asserting, for example, that every society needed to have a religion of some sort to establish common values. This got the theorists into the obvious trouble of explaining how societies had such different religions, and some no apparent religion at all. More sophisticated functionalism, by contrast, recognized that while the social function might be indispensable, the social institution was not. In Merton's summary:

The same function [may] be diversely fulfilled by alternative items. Functional needs are here taken to be permissive, rather than determinant, of specific social structures. Or, in other words, there is a range of variation in the structures which fulfill the function in question. In contrast to [the] concept of indispensable cultural forms (institutions, standard practices, beliefsystems, etc.) there is, then, the concept of functional alternatives (1957, 3334).

What does this mean for the joint activities which are the context for arguments? While it may be that society needs to promote (say) mutual understanding somehow, we can expect there to be many functional alternatives for accomplishing this. No single set of norms, therefore, can lay claim to being necessary for achieving the desired function. Thus the move in function claim assertion (c), from general function to specific norms, is illegitimate.

Consider this analogy. To perpetuate themselves, most societies depend on sexual reproduction. The young of the human species cannot survive on their own, however. To achieve the social good of survival, a society must therefore institute child-rearing practices. Norms must specified which impose on someone in society the burden of supporting the young, helping them grow, defending them against dangers. Who that ends up being is quite varied. Society can specify norms assigning upbringing responsibilities to those most qualified, for example—certified child care specialists. Or society can specify norms assigning upbringing responsibilities to those with the most stake in perpetuation of society-say, senior members of the child's social group. Or society can specify norms assign 
upbringing responsibilities to the biological parents of the child; that at least picks out definite individuals, and so may lessen disputes. Or... . Further, there are important normative variations between societies in what the upbringing requires, how long it takes, where it occurs and so on; within very general limits, all these variables are up for grabs.

Apply this then to the institution of a norm of argument: the burden of proof. Arguments which have just been brought to birth need support. To achieve the social good of argument survival - a necessary precondition for arguments to achieve their broader social function(s) — a society must therefore institute argumentrearing practices. Norms must be specified which impose on someone in society the burden of supporting arguments, helping them grow, defending them against objections. But who? Society can specify norms assigning argument upbringing responsibilities to those most qualified — say, an elite corps of argument professionals in a system of National Argument Clinics, or perhaps the punditocracy. Or society can specify norms assigning argument upbringing responsibilities to those with the most at stake in the argument's growth-say, senior members of the ideological faction whose position the argument supports. Or society can impose norms assigning upbringing responsibilities to the person who engendered the argument, its proponent. Or.... And similar normative alternatives arise in specifying what objections must be met, how deep must be the response and so on. Within very general limits, a variety of normative arrangements regarding burden of proof can promote the survival of an argument, and thus its ability to perform an asserted function.

The existence of functional alternatives-multiple, yet functional ways of organizing the joint activity in which arguments arise-means that a single, determinate set of norms cannot be derived from a function of argument. Now, it may be that theorists making function claims could defend their derived norms, not as necessary to achieve the alleged function of argument, but as the most efficacious or efficient way to do so. In reply I say again: Fine! But show me. How do you know that imposing on an arguer an obligation to answer just these objections optimally promotes the mutual understanding, the rational resolution of disputes, or any other posited social good?

\section{There is an alternative to a functional account of the contextual norms of argument}

Perhaps we would feel compelled to continue to make function claims if they were the only way to account for the context-dependent norms of argument. But there are alternatives to function claims in argument theory, as there were to functionalism in sociology.

The social scientific schools that developed in the 60's in opposition to functionalism were diverse, including Goffman's dramaturgical approach, 
Garfinkel's ethnomethodology, Sack's conversation analysis and Hymes' ethnography of communication, in addition to the Marxist-inspired conflict theories noted above. Within this diversity, however, some general tendencies can be discerned. Anti-functionalist theorists often understood social order as an ongoing achievement. If something like an argumentative exchange displays regular features, it is because the participants work hard to make it so. To locate social order, these theorists therefore focused on the "micro" level of specific interactions, instead of the "macro" level of an entire society and its institutions. And they explained these interactions by reference to the choices of individual agents, who act strategically to achieve their goals.

Consider the following as a representative anecdote; a story told about of Harvey Sacks and his invention of a new approach to the study of talk:

It was during a long talking walk in the late winter of 1964 that Sacks mentioned to me a 'wild' possibility that had occurred to him. He had previously told me about a recurrent and much discussed practical problem faced by those who answered phone calls to the Suicide Prevention Person by suicidal persons or about them - the problem of getting the callers to give their names. Now he told me about one call he had seen/heard which began something like this:

A: This is Mr Smith, may I help you.

B: I can't hear you.

A: This is Mr Smith [emphasized].

B: Smith.

After which Mr Smith goes on, without getting the caller's name. And later, when Mr Smith asks for the caller's name, the caller resists giving it. On the one hand, Sacks noted, it appears that if the name is not forthcoming at the start it may prove problematic to get. On the other hand, overt requests for it may be resisted. Then he remarked: Is it possible that the caller's problem in hearing is a methodical way of avoiding giving one's name in response to the other's having done so? Could talk be organized at that level of detail? And in so designed a manner? (Sacks, 1995, xvi-xvii).

What if we approached argument in parallel fashion? Is it possible that much of what we see in argumentative discourse are methodical ways of avoiding, and also imposing, obligations of various sorts? Could argumentative talk be organized at that level of detail? And in so designed a manner?

One line of recent scholarship answers "yes" to these questions. Work by Fred Kauffeld (1995, 1998, 2001, 2002b, 2003), Jean Goodwin (2001a, 2001b, 2002a, 2002b, 2003, 2005a, forthcoming), Beth Manolescu (2005a, 2005b, 2006) and most recently Bob Pinto (2004) gives accounts of the pragmatic or contextdependent norms as crafted by agents acting strategically in specific interactions; we undertake what has been dubbed a design approach (Goodwin, 2002b). The basic conception of this approach can be summarized in three propositions, standing in contrast to the three propositions of a function claim. 
$\mathrm{a}^{\prime}$ The determinative feature of the context of an argument is the talk in and through which the argument is made.

We do not assume that context comes already organized into social forms like "dialogues" or "critical discussions." Instead, we take the talk through which, and within which, arguments are deployed as the primary means by which people organize a context for their interaction. Because of this, we do not expect to give a single, uniform account of the norms of argument in all contexts, or even a cluster of possible accounts, but instead recognize diverse normative environments created by diverse histories of talk.

$\mathrm{b}^{\prime}$ A speaker so designs that talk as to create for the recipient(s) reason to respond as he desires.

We do not take it for granted that argumentative talk is consequential. Quite the contrary, we observe that it is difficult for speakers to achieve their goals, and we try to build accounts of how they overcome these difficulties. Specifically, we ask how a speaker's uttering some sentences can reasonably be expected to have the consequences he wants-or indeed any consequences at all-especially from autonomous recipients who are likely to disagree. We find that speakers use substantial skill and effort in designing their talk so as to create reasons for the recipients to respond as desired. To put it in shorthand, instead of assuming that argumentative talk is functional, we inquire how it is designed to have force.

$c^{\prime}$ The norms of argument include those obligations (standards, ideals, etc.) that his argument must meet (live up to, realize etc.) in order for his talk to have force.

It is a common strategy for a speaker to create force by creating a local "normative terrain" in which the response he desires is manifestly obligatory (ideal, right, prudent etc.). For example, a speaker often would like to oblige his the recipients of his argument to pay attention to it; then perhaps to seriously consider it, to respond to it, and eventually to make up their minds about it. As it happens, strategies which impose obligations on interlocutors commonly require the speaker himself to commit to producing arguments of a certain quality - that is, to undertake a burden of proof. In other words, it will often turn out that the same "normative terrain" that obligates the recipients to respond also obligates the speaker to argue well. These quality requirements are among the context-dependent or pragmatic norms of argument.

Now, undoubtedly those of us who put forward "force claims" along the lines of $\left(a^{\prime}\right),\left(b^{\prime}\right)$ and $\left(c^{\prime}\right)$ will encounter some problems. I invite the reader to take up the essays cited above, and start compelling us to address them.

\section{Concluding remarks}

Some may feel a lingering nostalgia for the critical discussion or other dialogue types, at least as ideals to be cultivated. And there are undoubtedly a wide range of 
pre-existing social institutions (speaking broadly) within which arguments can be found. These may include speech genres (the conference paper), formally organized occasions (the criminal trial), explicit rule sets (Roberts' Rules of Order) and undoubtedly many other more or less enduring patterns of expectations (including norms) about how argumentative talk will go. What can a design approach say about these?

As Sally Jackson argued in a seminal Alta paper, even a theorist committed to a "social-level" analysis of argumentative talk can benefit from the results of an "individual-level" analysis as well (1992 [1983]). Consider then two ways in which a committed functionalist might find in the design approach a useful complement to his own theorizing.

First, argumentative institutions from the conventions of casual politeness up to full-fledged goal-directed joint activities (if any) are themselves the products of human ingenuity. They have been created by design to achieve our purposes. We need to investigate them to account for their designs, to determine (not assume) their actual consequences, intended and unintended, and to re-engineer them if necessary to achieve what we want them to achieve. The work of Sally Jackson (1998, 1999) and Mark Aakhus (2002) is showing the way here.

Second, to function at all, argumentative institutions need the support only individual argumentative craftsmanship can supply. Even if one participant knows that the other understands what a critical discussion (or whatever) ought to bethat is, even if some institution is "at hand"-getting that other into it may take substantial discursive work. It is striking, for example, how much force it takes to get people into child custody mediation - a paradigmatic example of rational dispute resolution. Participants are under court order, threatened with penalties, and a third party is present who continually intervenes to push the participants into compliance with the speech norms. Something similar seems to be the case for debates between U.S. presidential candidates, which commonly take weeks of negotiation and hundreds of pages of rules to get started, and which may only take place because the consequences of appearing to chicken out are so severe. These are extreme cases, perhaps; but in general, they do suggest that we need to investigate the strategic resources participants have for making the social institutions or social ideals for argument effective in an imperfect world. Scott Jacobs (1999, 2000) and again Mark Aakhus (2003) have been pointing us in this direction.

The functionalism debate in sociology, like scholarly debates generally, faded out without resolution Indeed, after a time, functionalism revived; now there is a neofunctionalist school of sociological theorizing that I don't pretend to understand.

I am calling for nothing more here in argumentation studies. Douglas Walton has led us in the right direction by turning us to the pragmatic study of argument. But now that we have proceeded a ways down this path, we need to stop making naïve function claims. This might mean avoiding function talk entirely-avoiding throwing out words like "dialogue, cooperation, the purpose of argumentation" 
and so on, and trying a design approach instead. Or if not this, then let the function talk become more sophisticated, defending assumptions (a), (b) and (c) against the objections raised here. ${ }^{7}$

\section{Notes}

${ }^{1}$ Roughly: by "joint activity" I mean one in which the participants mutually recognize that their individual efforts are for the sake of an activity that they share. A tango is a joint activity; a war is not.

${ }^{2}$ Functional items are often composed of other functional items and themselves contribute to larger functions, as mitochondria contribute to cells which contribute to organs which contribute to the flourishing of the organism. But it is sloppy to speak of "argument having the function of resolving disputes," since at best arguments-together with a lot of other talk-contribute to a joint activity, and it is the joint activity which has that function. The pragma-dialecticians are clear about this; some other functionalists aren't. Still, talk of argument having the function of disagreement resolution (or other aim), leaving out the joint activity, serves as a convenient shorthand, and I will occasionally follow it here.

${ }^{3}$ What Grice really meant is beyond the scope of this paper, although it should be noted that it is possible to pursue a Gricean account of the pragmatics of argumentative talk without asserting an obligation to cooperate; see Kauffeld, 2002a.

${ }^{4}$ The controversy is usefully anthologized in Demerath \& Peterson (1967) and reviewed by Abrahamson (1978) and Baert (1998).

${ }^{5}$ One response to this problem is to reduce the number of collective goals a given instance of dialogue is trying to achieve. Walton suggests this approach for political debate, proposing that talk in this kind of joint activity should be analyzed as if it were the preferred type of dialogue, a critical discussion $(1998,224-5)$. This simplification indeed allows the theorist to derive a single set of norms, but only at the cost of giving up multi-functionalism, with its empirical flexibility. ${ }^{6} \mathrm{I}$ take it that something like this objection is the one that Hansen has been addressing to Johnson's theory of the "dialectical tier" for the past few years. The obligation to answer objections seems an "imperfect obligation," like the obligation of charity: obliging some kind of response in general, but not imposing an obligation in specific to meet this objection and not that one.

${ }^{7}$ I thank David Godden, an anonymous reviewer and an audience at the 2005 OSSA conference for their help in refining the argument of this paper

\section{References}

Aakhus, M. (2002). Modeling reconstruction in groupware technology. In F.H. van Eemeren (Ed.), Advances in pragma-dialectics (pp. 121-136). Amsterdam: Sic Sat.

Aakhus, M. (2003). Neither naïve nor critical reconstruction: Dispute mediators, impasse, and the design of argumentation. Argumentation, 17, 265-290.

Abrahamson, M. (1978). Functionalism. Englewood Cliffs, NJ: Prentice Hall.

Baert, P. (1998). Social theory in the Twentieth Century. New York: New York University Press.

Davis, K. (1967). The myth of functional analysis as a special method in sociology and anthropology. In Demerath \& Peterson (Eds.), System, change \& conflict (pp. 379402). New York: Free Press. 
Dore, R.P. (1967). Function and cause. In Demerath \& Peterson (Eds.), System, change \& conflict (pp. 403-419). New York: Free Press.

Demerath, N.J., \& Peterson, R.A. (1967). System, change \& conflict. New York: Free Press.

Elster, J. (1982). Marxism, functionalism, and game theory. Theory and Society, 11, 453482.

Eemeren, F.H. van, Grootendorst, R. \& Snoeck Henkemans, F. (1996). Pragma-dialectics and critical discussion. In Fundamentals of argumentation theory: A handbook of historical backgrounds and contemporary developments (pp. 274-311). Mahwah, NJ: Lawrence Erlbaum.

Fine, G. (2001). Gifted tongues, Princeton, NJ: Princeton University Press.

Freeman, J. (1991). Dialectics and the macrostructure of argument. Berlin: Foris.

Gaskins, R.H. (1992). Burdens of proof in modern discourse. New Haven, CN: Yale University Press.

Gilbert, M.A. (1997). Coalescent argumentation. Mahwah, NJ: Lawrence Erlbaum.

Godden, D.M. (2005). Deductivism as an interpretive strategy: A reply to Groarke's recent defense of reconstructive deductivism. Argumentation and Advocacy, 41, 168-183.

Goodnight, G.T. (1979). The liberal and the conservative presumptions: On political philosophy and the foundation of public argument. In J. Rhodes \& S. Newell (Eds.), Proceedings of the Summer Conference on Argumentation. Annandale, VA: Speech Communication

Goodwin, J. (2001a). Cicero's authority. Philosophy \& Rhetoric, 34, 38-60.

Goodwin, J. (2001b) The noncooperative pragmatics of arguing. In E.T. Nemeth (Ed.), Pragmatics in 2000: Selected papers from the 7th International Pragmatics Conference (Vol. 2, pp. 263-277). Antwerp: International Pragmatics Association.

Goodwin, J. (2002a). Designing issues. In F.H. van Eemeren \& P. Houtlosser (Eds.), Dialectic and rhetoric: The warp and woof of argumentation analysis (pp. 81-96). Dordrecht: Kluwer.

Goodwin, J. (2002b). One question, two answers. In H.V. Hansen et al. (Eds.), Argumentation and its Applications. Windsor: Ontario Society for the Study of Argumentation, CD-ROM.

Goodwin, J. (2003). Manifestly adequate premises. In J.A. Blair et al. (Eds.), Informal Logic @ 25. Windsor: Ontario Society for the Study of Argumentation, CD-ROM.

Goodwin, J. (2005a). Designing premises. In F.H. van Eemeren \& P. Houtlosser (Eds.), The practice of argumentation (pp. 99-114). Amsterdam: Walter Benjamins.

Goodwin, J. (2005b). What does arguing look like?' Informal Logic, 25, 79-93.

Goodwin, J. (Forthcoming). Actually existing rules for closing arguments. In F.H. van Eemeren et al. (Eds.), Proceedings of the Sixth International Conference of the International Society for the Study of Argumentation. Amsterdam: Sic Sat.

Govier, T. (1987). A new approach to charity. In Problems in argument analysis and evaluation (pp. 133-158). Dordrecht: Foris.

Jackson, S. (1992 [1983]). The arguer in interpersonal argument: Pros and cons of individual-level analysis. In W.L. Benoit, D. Hample, \& P.J. Benoit (Eds.), Readings 
in argumentation (pp. 513-521). Berlin: Foris. Originally published in D. Zarefsky, M.O. Sillars, \& J. Rhodes (Eds.), Argument in transition: Proceedings of the third Summer Conference on Argumentation. Annandale, VA: Speech Communication Association.

Jackson, S. (1998). Disputation by design. Argumentation, 12, 183-198.

Jackson, S. (1999). The importance of being argumentative: Designing disagreement in to teaching/learning dialogues. In F. H. van Eemeren, R. Grootendorst, J. A. Blair, \& C. A. Willard (Eds.), Proceedings of the Fourth International Conference of the International Society for the Study of Argumentation (pp. 392-396). Amsterdam: Sic Sat.

Jacobs, S. (1999). Argumentation as normative pragmatics. In F. H. van Eemeren, R. Grootendorst, J. A. Blair, \& C. A. Willard (Eds.), Proceedings of the Fourth International Conference of the International Society for the Study of Argumentation (pp. 397-403). Amsterdam: Sic Sat.

Jacobs, S. (2000). Rhetoric and dialectic from the standpoint of normative pragmatics. Argumentation, 14, 261-286.

Johnson, R. H. (2000). Manifest rationality: A pragmatic theory of argument. Mahwah, NJ: Lawrence Erlbaum.

Kauffeld, F. J. (1995). The persuasive force of arguments on behalf of proposals. In F. H. van Eemeren, R. Grootendorst, J. A. Blair, \& C. A. Willard (Eds.), Analysis and evaluation: Proceedings of the Third ISSA Conference on Argumentation (Vol. II, pp. 79-90). Amsterdam: Sic Sat.

Kauffeld, F. J. (1998). Presumptions and the distribution of argumentative burdens in acts of proposing and accusing. Argumentation, 12, 245-66.

Kauffeld, F. J. (2001). Argumentation, discourse, and the rationality underlying Grice's analysis of utterance-meaning. In E.T. Nemeth (Ed.), Cognition in language use: Selected Papers from the 7th International Pragmatics Conference (Vol. 1, pp. 149163). Antwerp: International Pragmatics Association.

Kauffeld, F.J. (2002a). Grice without the cooperative principle. In H.V. Hansen et al. (Eds.), Argumentation and its Applications. Windsor: Ontario Society for the Study of Argumentation, CD-ROM.

Kauffeld, F.J. (2002b). Pivotal issues and norms in rhetorical theories of argumentation. In F.H. van Eemeren \& P. Houtlosser (Eds.), Dialectic and rhetoric: The warp and woof of argumentation analysis (pp. 97-118). Dordrecht: Kluwer.

Kauffeld, F. J. (2003). The ordinary practice of presuming and presumption, with special attention to veracity and the burden of proof. In F. H. v. Eemeren, J. A. Blair, C. A. Willard \& A. F. Snoeck Henkemans (Eds.), Anyone with a view: Theoretical contributions to the study of argumentation (pp. 133-146). Dordrecht: Kluwer .

Lakoff, G. \& Johnson, M. (1980). Metaphors we live by. Chicago: University of Chicago Press.

Manolescu, B. (2005a). Norms of forcibleness. In D. Hitchcock (Ed.), The uses of argument: Proceedings of a conference at McMaster University (pp. 336-345). Hamilton: Ontario Society for the Study of Argumentation.

Manolescu, B. (2005b). Norms of presentational force. Argumentation and Advocacy, $41,139-51$. 
Manolescu, B. (2006). A normative pragmatic perspective on appealing to emotions in argumentation. Argumentation, 20, 327-343.

Merton, R. (1957). Manifest and latent functions. In Social theory and social structure (pp. 19-84). Glencoe, IL: The Free Press.

Pinto, R.C. (2004). Reasons, contexts and expectations of rebuttal. A paper presented at the National Communication Association Convention, Chicago.

Sacks, H. (1995). Lectures on conversation. Malden, MA: Blackwell.

Sanders, L.M. (1997). Against deliberation. Political Theory, 25, 347-377.

Sanders, R.E. (2005). Introduction: LSI as subject matter and as multidisciplinary confederation. In K.L. Fitch and R.E. Sanders (Eds.), Handbook of language and social interaction (pp. 1-14). Mahwah, NJ: Lawrence Erlbaum.

Schiffrin, D. (1984). Jewish argument as sociability. Language in Society, 13, 311-335.

Tannen, D. (1998). The argument culture. New York: Random House.

Walton, D. (1992). Plausible argument in everyday conversation. Albany, NY: State University of New York Press.

Walton, D. (1995). A pragmatic theory of fallacy. Tuscaloosa, AL: University of Alabama Press.

Walton, D. (1996a). Argument structure: A pragmatic theory. Toronto: University of Toronto Press.

Walton, D. (1996b). Argumentation schemes for presumptive reasoning. Mahwah, NJ: Lawrence Erlbaum.

Walton, D. (1998). The new dialectic: Conversational contexts of argument. Toronto: University of Toronto Press.

Walton, D. (2006). Fundamentals of critical argumentation. Cambridge: Cambridge University Press.

Walton, D. \& Krabbe, E.C.W. (1995). Commitment in dialogue: Basic concepts of interpersonal reasoning. Albany, NY: State University of New York Press.

Young, I.M. (1996). Communication and the other: Beyond deliberative democracy. In S. Benhabib (Ed.), Democracy and difference: Contesting the boundary of the political (pp. 120-135). Princeton, NJ: Princeton University Press.

Jean Goodwin Department of English

223 Ross Hall

Iowa State University

Ames, Iowa 50011

U..S.A.

goodwin@iastate.edu 